\title{
The Pathogenesis of Gastric Carcinoma
}

\author{
Elroy Patrick Weledji
}

Corresponding author:

Elroy Patrick Weledji, BSc, MSc, MBBChBAO, FRCS

Senior lecturer in Anatomy and

Clinical Surgery, University of Buea

S. W. Region, Cameroon

PO Box 126, Limbe, S.W. Region

Cameroon.

Tel 237699922144

E-mail: elroypat@yahoo.co.uk

\section{Abbreviations:}

CAG - Chronic Atrophic Gastritis;

CDH1 - E-cadherin;

DNA - Deoxyribonucleic Acid;

EGF - Epithelial Growth Factor;

FAP - Familial Adenomatous

Polyposis;

GOJ - Gastro-Oesohageal Junction;

H. Pylori - Helicobacter Pylori;

HDCG - Hereditary Diffuse Gastric

Cancer;

HNPCC - Hereditary Non-Polyposis

Colorectal Cancer;

IM - Intestinal Metaplasia;

LOH - Loss of Heterozygosity:

MALT - Mucosa-Associated Lymphoid

Tissue;

MIS - Microsatellite Instability;

TGF $\alpha$ - Tumour Growth Factor- $\alpha$;

Vac A - Vacuolating Antigen A;
Senior lecturer in Anatomy and Clinical Surgery, University of Buea, S. W. Region, Cameroon

\section{ABSTRACT}

Gastric cancer is one of the leading causes of cancer mortality in the world. Gastric adenocarcinomas account for more than $95 \%$ of gastric tumours, and these epithelial tumours result from the accumulation of multiple genetic defects which leads to uncontrolled growth. The most plausible pathway for gastric carcinoma indicates that the underlying mechanisms may be different for the diffuse and intestinal types of tumour. The distinct subtypes - proximal, diffuse and distal gastric cancer that are different from a histological and epidemiological standpoint, can also distinguished by gene expression data. The disease classification of the epithelial tumours may lead to different treatment paradigms for individual gastric cancer subtypes. The changes present can be classified as consisting of abnormalities in DNA content, the karyotype (including allele loss), oncogene and tumour suppressant gene expression (or deletion), cell cycle regulation and DNA repair genes. This article reviewed the biological/ molecular differences of the gastric carcinoma subtypes, the risk factors and precursors of gastric carcinoma and the implications on early diagnosis and response to adjuvant treatment. Despite the heterogeneity of multiple somatic alterations in the neoplastic lesion, the implication of a molecular classification is its exploitation to identify prognostic and predictive biomarkers and to identify targets for therapy.

Key words: gastric carcinoma, pathogenesis, molecular, epidemiology

\section{INTRODUCTION}

Gastric cancer is the third most common malignancy worldwide with 974,000 new cases in the year 2000, although in recent decades a decline has been observed in its incidence and mortality (1-3). It is the second most common cause of cancer-related mortality worldwide with 700,349 deaths annually (1). The incidence of gastric cancer was 24,590 cases and 10,720 deaths in the USA in 2015 (4) with the case fatality rate of 75\% (5). It is the leading cause of cancer death in Japan (50,562 in 2004), although the incidence of advanced gastric cancer and mortality have decreased in the last decade in Japan because of endoscopic screening and early diagnosis $(6,7)$. The most dramatic fall in the incidence of distal gastric cancer, by 8 -fold in the last 50 years, occurred in the affluent Western countries, predominantly Caucasian population, and low population density regions, such as USA, Canada, Australia, and New Zealand. There was a less dramatic decline in Western Europe, however (8-10). Pathologically, gastric adenocarcinoma may be distinguished according to the 
Lauren's classification into intestinal, diffuse, or mixed subtype (11). Epidemiologically, intestinal gastric cancer, particularly of the antrum, is strongly associated with chronic inflammation (i.e. atrophic gastritis) (12, 13) which is often a consequence of chronic infection with Helicobacter pylori (H. Pylori) $(14,15)$. Conversely, inflammation is characteristically absent in the development of Lauren's diffuse type gastric cancer, particularly when the latter is a result of a germ line mutation in $\mathrm{CDH} 1$ (16). Anatomically, proximal gastric cancer may be classified as a third type of gastric cancer, as tumours of the gastric cardia/gastro-oesohageal junction (GOJ), for which inflammation of a different type (i.e. chronic gastric acid/ bile reflux) may be the driving force for carcinogenesis $(17,18)$. Proximal/ GOJ tumours are also usually not diffuse in histology and similar to distal non-diffuse gastric cancer. Obesity and gastric reflux are risk factors.

\section{MOLECULAR EPIDEMIOLOGY}

Gastric adenocarcinoma is a tumour derived from the lining mucosa which usually presents late in its natural history. The most widely accepted histological classification of gastric carcinoma is the one created by Lauren, who divided the tumours into two main types. Those which formed glandular structures were known as intestinal (53\%) whereas those without any structure and secreting mucin were known as diffuse type carcinomas (33\%). The remaining $14 \%$ had a mixed appearance with elements from both types and were regarded as unclassified (11). The classification of gastric carcinoma has proved most useful epidemiologically as the two types may represent different diseases and as a result have different aetiological factors. The intestinal type of gastric cancer has presents substantial interest from an epidemiological standpoint. The intestinal type which is thought to arise from intestinal metaplasia (IM) in the stomach is more prevalent in the older age group. This contrasts with the diffuse type which has an equal sex incidence and occurs at a younger age. The intestinal type is more common in areas of high incidence whereas the diffuse type occurs equally irrespective of incidence rates. Furthermore, the excess incidence of intestinal type is associated with the high mortality seen in areas of high incidence (18). Conversely the reduction in mortality in areas of decreasing incidence is associated with a reduction in incidence of the intestinal type (19). Moreover, this reduction is associated with the decrease in incidence in the distal stomach suggesting that the intestinal type is a disease of the gastric antrum. This subtype, which remains endemic in the Far East, parts of South America, and Eastern Europe, is principally a disease of the distal stomach associated with chronic gastritis, intestinal metaplasia, and mucosal atrophy. The high incidence rates in these regions is thought to be due to continuing high rates of Helicobacter pylori infection, adverse dietary factors (nitrosamines), and genetic predisposition (12, 21-23). The increasingly occurring subtype found in Western countries is commonly found near the gastrooesophageal junction (GOJ) and is associated with significant gastritis $(19,20,24,25)$ Over the last 30 years, the marked increase in incidence of GOJ was associated with the downward migration of oesophageal tumours and proximal shift of gastric tumours $(6,7)$. The epidemiological profile suggests a similar aetiology and is consistent with the two cancers having a similar phenotype and p53 gene mutation (6). GOJ cancer is the fastest increasing solid malignancy of adult life in the West, with an increasing incidence of $3 \%-4 \%$ per annum (2-4). This suggests that it is certain dietary or environmental factors which are important in the development of the intestinal lesion. On the other hand, the diffuse type, whose incidence tends to decrease, is often related to hereditary factors. Because the much lower incidence of gastric cancer in the United States and other Western countries does not justify screening, endoscopic surveillance has been proposed and advocated for populations at risk, including AfricanAmericans, native Americans, and immigrants from highrisk regions (22). The disease thus presents late in its natural history in these countries.

\section{PATHOGENESIS OF GASTRIC CANCER}

The pathogenesis of gastric cancer is complex and multifactorial. Environmental factors are required to effect multistage progression to malignant transformation according to the Correa hypothesis $(9,26,27)$.

\section{Risk factors}

The risk factors for gastric cancer include low socioeconomic status, diet (nitrosamines- dye, cured meat, fish, alcohol, tobacco), blood group A, obesity (2-fold increase risk of gastric cancer), genetic predisposition [E-Cadherin mutations, hereditary diffuse gastric cancer (HDCG); associated with lobular breast cancer] $(9,28)$. Most adenocarcinomas are sporadic and associated with consumption of heavily salted and preserved foods (e.g. nitrates in pickled or salted foods such as bacon), low intake of fruits and vegetables and use of tobacco and alcohol. Dietary salt enhances the conversion of nitrates to carcinogenic nitrosamines in the stomach. 
Salt and nitrates (NO3) converted to nitrites (NO2) are caustic to the stomach, delay gastric emptying, and cause chronic atrophic gastritis (9).

\section{Precursors}

\section{Chronic atrophic gastritis}

The development of gastric adenocarcinoma of the intestinal type is thought to progress sequentially through four stages: non-atrophic gastritis, multifocal atrophic gastritis, IM, and dysplasia. Correa et al have proposed that there is a progression from normal gastric mucosa to carcinoma in high risk populations (29). The initial change is early onset superficial gastritis which, although reversible, is triggered by a variety of agents. H. pylori, chemical irritants (reflux/ ingested), autoimmune disease (pernicious anaemia) all cause inflammatory damage to the gastric mucosa, resulting in atrophic gastritis and intestinal metaplasia $(30,31)$. The progress to chronic gastritis may be associated with varying degrees of atrophy. Atrophic gastritis predisposes a high gastric $\mathrm{pH}$, bacterial overgrowth and conversion of nitrates to nitrites. The resulting increase in nitrosamines damages the deoxyribonucleic acid (DNA) of mucosal cells, further promoting metaplasia and neoplasia. Alongside nitrogen compounds found in food and drugs bile acids degrade these nitrosamines to nitric oxide mutagens, which initiate small intestine metaplasia or promote dysplasia from colonic metaplasia. Duodenal reflux may contribute to intestinal metaplasia as it contains caustic bile salts that destroy the mucosal barrier which normally protects the stomach. While IM may occur in all areas of gastric atrophy, it occurs particularly in areas where metaplasia is similar to large bowel epithelium where dysplasia and hence carcinoma of the intestinal type may supervene (32-33). In high risk areas both IM and chronic gastritis are found in association with intestinal type cancer. Other evidence comes from studies of chronic gastritis associated with autoimmune pernicious anaemia. Patients with chronic atrophic gastritis (CAG) associated with autoimmune pernicious anaemia are at risk from gastric cancer. Moreover, the gastric mucosa the early stage of the disease has similar features of intestinal metaplasia. IM incidence in patients with the diffuse type of cancer is no different from the general population $(34,35)$. Intestinal metaplasia (IM) of the stomach has been shown to increase the relative risk of gastric cancer by a factor of 4.58 when compared to type 1 (36). Both precursor lesions are common in areas of high incidence. Endoscopic surveillance has been proposed and advocated for populations at risk.

\section{Helicobacter Pylori}

H. pylori is a micro-aerophilic, Gram negative, spiral mictro-organism, classed by WHO as Group 1 carcinogen. A $100 \%$ infection results in 6-fold increase in incidence of gastric cancer $(14,37)$. The $H$. pylori that carry the Cag A gene product cytotoxin associated vacuolating antigen $A$ (Vac A) also causes gastric B-cell mucosa-associated lymphoid tissue (MALT) lymphoma (38). Despite the fact that the stomach does not normally have any lymphoid tissue like the terminal ileal Peyer's patches from which lymphoid malignancy could arise, recent studies have demonstrated that up to $90 \%$ of the gastric MALT type lymphoma were associated with $H$. pylori infection. This has suggested that the bacterial antigens may not only initiate gastritis but also perpetuate the immunological drive from which the lymphomatous process develops $(39,40)$. The sub-sequent development of monoclonal lymphocytosis requires accumulation of genetic abnormalities (41). It is important to note that regression of primary low grade B-cell gastric lymphoma of MALT type occurs after eradication of Helicobacter pylori but the results of similar trials on gastric carcinoma are awaited (42). H. pylori infection causes cell loss due to urease, ammonia, acetaldehyde activity, resulting from chemotactic effect on inflammatory cells releasing oxygen metabolites. The resulting loss of fundic glands leads to hypochlorhydria and proliferation of $\mathrm{H}$. pylori. Chronic H. pylori infection induces chronic inflammation in the gastric mucosa, which may progress to atrophy and IM. The latter is a precursor to gastric adenocarcinoma (14, 43). IM initially appears at the antrum-gastric body junction, especially at the gastric incisura angularis. As atrophy and metaplastic changes advance, they tend to extend to the antrum and gastric body, and dysplastic foci may eventually appear.

\section{Gastric remnant}

Following previous gastrectomy, there is a $2 \%$ increase in the risk of gastric cancer, usually found at the stomal site $(35,44)$. Those who are at most risk are patients who have undergone surgery before the age of 40 and who have had a post surgery interval of 15-20 years $(45,46)$. Although alkalinity may play a role, the risk of developing this type of cancer is increased in countries with a high intrinsic rate of gastric cancer but apparently not in those with a lower rate (47-50). In addition, cases of lymphoma of the stomach are now being described in the gastric stump (51). Nonetheless, those patients who had undergone surgery for gastric malignancy would have exhibited precancerous lesions such as atrophic gastritis and IM, and the possibility of 
anastomotic recurrence is higher than for the patients who had undergone benign gastric surgery $(38,49,52)$. At present, there are no other recognized good markers of gastric dysplasia or cancer and residual premalignant (type III) IM may be the only marker for anastomotic recurrence of gastric cancer (38,53-55). Micro RNAs are currently being evaluated as a specific diagnostic and prognostic marker (55).

\section{Gastric polyps}

Gastric polyps are found with increasing incidence in the elderly, and in some series they are present in up to $7 \%$ of patients over 80 years old (56). The classification is important as it indicates whether or not they are premalignant or are just incidental and sometimes associated with tumours $(57,58)$. Gastric mucosal polyps fall into three main groups; the hyperplastic polyps, fundic gland polyps or neoplastic polyps (adenomas). The hyperplastic subtype represents 80$85 \%$ of all gastric polyps, and is more common in the antrum rather than the gastric body. It generally consists of usually multiple polyps, less than $1 \mathrm{~cm}$ in diameter and has no increased risk of cancer (59). Hyperproliferative hamartomas occur in fundic glands but with no increased risk of cancer (60). Gastric polyps may be associated with familial adenomatous polyposis (FAP) but they are more commonly sporadic. Malignant change may occur in $40 \%$ of those neoplastic adenomas greater than $2 \mathrm{~cm}$ (61) The gastroduodenal polyps associated with FAP have an increased risk of malignant transformation to duodenal and periampullary carcinoma $(61,62)$

\section{Gastric epithelial dysplasia}

Dysplasia may occur in an epithelium which shows intestinal metaplasia and may be flat, depressed or polypoid $(38,62)$. The natural history (mild/ moderate/ severe dysplasia is not a relentless march to carcinoma. There is a regression to normal in $60-70 \%$ of mild to moderate cases, but regression is less common in severe cases with $50-60 \%$ progressing to invasive carcinoma in this category (63). It is important to note that low grade dysplasia can be confused with inflammatory atypia, which can regress with acid suppression. The possibility of malignant transformation of gastric ulcers is controversial. Only 1-3\% of gastric ulcers with an atrophic gastritis are associated with dysplasia (64). There are several problems associated with histological interpretation which include distinguishing regenerative atypia from true dysplasia, the ability to differentiate high- grade dysplasia from intramucosal carcinoma, a lack of experience due to the rarity of dysplasia (especially in low incidence areas) and the problem of sampling identical areas in the gastric mucosa on follow-up endoscopy. The natural history of dysplasia also compounds the potential 'premalignant' problem of regression. A diagnosis of severe dysplasia is a frequent marker of co-existent cancer, with $50 \%$ of the tumours being diagnosed within 3 months of the initial finding of dysplasia on biopsy. This is accompanied by a gross endoscopic lesion by erosion ulcer or polyp (64). The epidemiological evidence would suggest that ulcers do not have a significant role in gastric carcinogenesis. It is thought that less than $1 \%$ of chronic peptic ulcers will have undergone malignant transformation. Few long term studies of peptic ulcers are available and these have shown a relative risk of developing cancer no more than twice that of the normal population (65).

\section{Menetrier's disease}

\section{(Hypertrophic gastropathy)}

This is a rare cause of hypertrophic rugal gastropathy characterised by hyperplasia of the surface cells, hypochlorhydria and a protein- losing enteropathy. Approximately $10 \%$ are associated with gastric cancer, diagnosed either simultaneously or within 12 months. However, follow-up in a total of 16 cases shows the risk of malignancy to be low or negligible (66). A few cases have been associated with gastric dysplasia.

\section{Molecular aspects of gastric cancer}

Epithelial tumours result from the accumulation of multiple genetic defects which leads to uncontrolled growth. Modification of the tumour growth occurs as a result of the local effects of cytokines, growth factors and the interaction with the stromal components. A stepwise progression has been suggested, from the possible precursor lesions to cancer. Nevertheless, the initiating agents are unknown. The most plausible pathway for gastric cancer indicates that the underlying mechanisms may be different for the diffuse and intestinal types of tumour, respectively. There has been a steep rise in the knowledge of the genetic abnormalities in both gastric and oesophageal cancers (67-72). The changes which occur in these malignancies can be classified as consisting of abnormalities in DNA content, in the karyotype (including allele loss), oncogene and tumour suppressant gene expression (or deletion), of cell cycle regulation and finally of DNA repair genes. Loss of heterozygosity (LOH) studies have shown several chromosomal loci with significant allelic loss, thus indicating the possibility of harbouring a tumor suppressor gene which plays an important role in gastric tumorigenesis. Microsatellite instability (MIS) and associated alteration of the TGF-bIIR, 
Table 1 - Cancers affecting the stomach

\begin{tabular}{lc}
\hline Gastric adenocarcinoma & $>90 \%$ \\
\hline Gastric lymphoma & $5 \%$ \\
\hline Carcinoid & $3 \%$ \\
\hline GIST & $1 \%$ \\
\hline Liposarcoma & $<1 \%$ \\
\hline
\end{tabular}

IGFRII, BAX, E2F-4, hMSH3, and hMSH6 genes are also found in a subset of gastric carcinomas (73).

\section{Genetic pathway}

The heterogeneity of tumours is not only expressed in the morphological structure, but also in its DNA content as up to $30 \%$ of tumours show a mixed diploid and aneuploidy pattern. There are significant differences in the DNA content of tumours. For instance, tumours of the cardia display aneuploidy and have a poor prognosis (74). Despite this, diffuse cancers with their generally poor prognosis, tend to be less associated with aneuploidy than the intestinal type malignancies. The tumour suppressor gene p53, which is found on the short arm of chromosome 17, is thought to play a pivotal role in cell regulation and tumorigenesis. Its normal function is to put a brake on DNA replication and to act as a trigger for apoptosis, in response to significant DNA damage. Thus the $\mathrm{p} 53$ protein has roles in the repair of DNA and the induction of programmed cell death. Point mutations are the most frequent abnormality in this type of malignancy. Overall, genetic defects are noted in up to $60 \%$ of gastric tumours (75). Abnormalities of the proto-oncogenes are now being described, (75) which suggests they occur as early events in carcinogenesis. Comparative genomic hybridization analyses have identified several amplifications and losses of DNA copy numbers in gastric cancers. Loss of heterozygosity ( $\mathrm{LOH}$ ) in the proto-oncogene C-met continues to be present in up to $30 \%$ of intestinal cancers and correlates with peritoneal dissemination (70). Although their abundance only accounts for $<10 \%$ of all cellular kinases, many PTKs have been shown to be oncogenic once they lose their biological regulation either by gene amplification, somatic mutation, or viral activation.

\section{Growth factors}

$\mathrm{K}$-sam is a member of the fibroblastic growth factor receptor family, which is amplified in both diffuse and scirrhous carcinomas but not in other types of tumours
Table 2 - Precursors of gastric carcinoma

\begin{tabular}{l}
\hline Chronic gastritis \\
Intestinal metaplasia of gastric mucosa \\
Gastric polyps \\
Gastric remnants (postgastrectomy state) \\
Menetrier's disease \\
Chronic peptic ulcer \\
Gastric epithelial dysplasia \\
\hline
\end{tabular}

(66). In some tumours overexpression of c-erB-2 has been associated with more rapid metastases to the liver. Nevertheless, in other reports over expression had the reverse effect with patients experiencing longer survivals (72). Amplification and overexpression of the oncogene c-myc is found in both intestinal metaplasia and some cases of dysplasia as well as advanced gastric cancer, but not in early gastric cancer. The growth factors - tumour growth factor- $\alpha$, (TGF $\alpha$ ), epithelial growth factor (EGF), amphiregulin and interleukin $1 \alpha$, which modulate interactions between tumour cells and stroma, are overexpressed in tumours. A new oncogene cripto, a member of the EGF family is associated both with intestinal metaplasia and carcinoma and so far there is good correlation between the tumour stage and prognosis when the oncogene is expressed. Deletions of the crypto gene occur both in intestinal metaplasia and well-differentiated adenocarcinoma although over expression has been reported (73).

\section{Mismatch repair genes}

Abnormalities of the mismatch repair genes $(74,75)$ have been found in significant numbers of diffuse (64\%) type of adenocarcinomas, whereas only $7 \%$ of the intestinal type malignancies have similar defects. At present it is unclear whether this abnormality causes the accumulation of the genetic changes, of oncogenes or tumour suppressor genes in the same cancer (76). Gastric cancer has been observed to be part of the spectrum of neoplasms associated with germline mismatch repair gene (MMR) alterations that give rise to the hereditary non-polyposis colorectal cancer (HNPCC) entity. Comparative genomic hybridization analyses have identified several amplifications and losses of DNA copy numbers in gastric cancers (69).

\section{Metastasis-related gene}

The metastasis- related gene CD44 (77) is a linking protein the extracellular matrix and the cell surface. In cancers, this protein is defective and shows a significant difference in expression between intestinal and diffuse 
cancers. Another is nM23 which is thought to be a suppressor gene for metastasis and encodes the nucleotide diphosphate kinase and the c-myc transcription factor. Overexpression of this gene in a primary tumour is found to be related to the reduced risk of developing metastasis.

\section{Intestinal type}

Genetic instability of the normal cell leads to intestinal metaplasia in the well differentiated type (intestinal). Crypto overexpression, p53, adenomatous polyposis gene (APC, which is central to ordered cell motility), as well as K-ras mutations are thought to represent earlier events. K-ras on chromosome 12 induces cell growth by activating growth factor signal transduction. P53, APCLOH, c-met $6.0 \mathrm{~Kb}$ and bcl-2 gene loss occur as later events in the conversion to early gastric cancer. The change in the TGFb receptor and CD44 abnormal transcripts would lead to advanced gastric cancer. C-erB-2 amplification and reduction in $\mathrm{nM} 23$ will lead to metastasis $(71,73)$.

\section{Diffuse-type}

Diffuse gastric cancer is a poorly differentiated type of cancer which accounts for about $30 \%$ of all gastric carcinomas. Somatic mutations in E-cadherin (CDH1 gene), an adhesion molecule and a tumor suppressor protein, were found in more than $50 \%$ of these cases $(78,79)$. The genetic instability of the normal cell leads to the mutation of the tumour suppressor gene p53 and allele loss with loss of heterozygosity in the protooncogene C-met which leads to early gastric cancer. Cell adhesion molecule abnormalities such as those involving E-cadherin (CDH1) loss, TGFb over expression and CD44 abnormal transcripts would lead to advanced diffuse-type gastric cancer. The amplification of K-sam and reduction of $\mathrm{C}$-met reduction in $\mathrm{nM} 23$ also lead to metastasis $(71,73)$. Inactivating $\mathrm{CDH} 1$ mutations were also described in the germ line of families with hereditary diffuse gastric cancer (HDGC), an autosomaldominant disease characterized by clustering of early onset documented diffuse gastric cancer $(80,81)$.

Hereditary diffuse gastric cancer (HDGC) is a rare cause of early onset gastric cancer occurring in a younger age group. It is characterized by E-cadherin (CDH1) mutation, multi-centricity and linked to lobular breast cancer. HDGC families carry $C D H 1$ heterozygous germ line mutations. Their tumours acquire complete $\mathrm{CDH} 1$ inactivation through "2nd-hit" mechanisms. The 2nd hit in $\mathrm{CDH} 1$ frequently occurs via epigenetic changes in HDGC primary tumours and loss of heterozygosity (LOH) in metastases. This occurs most frequently via promoter hypermethylation (epigenetic modification) (81). The oncogenes/tumour suppressor genes p53 (Li-Fraumeni syndrome), BRCA2, PeutzJeghers and hereditary non-polyposis colorectal cancer (HNPCC) mutations increase risk. HDGC should therefore be managed by prophylactic gastrectomy.

\section{The new paradigm}

It is suggested that 'proximal non-diffuse', 'diffuse' and 'distal non-diffuse' gastric cancers may be distinguished at the genomic level (82). The clinical indications to support this hypothesis include the suggestions that (a) proximal gastric tumours have a worse prognosis stage for stage when compared to distal tumours (84), (b) Lauren's diffuse gastric cancers appear to have a different pattern of spread and behaviour than intestinal gastric adenocarcinoma (85), and (c) Her-2 over expression incidence is different between intestinal and diffuse types of gastric cancer. Her2 amplification is most prevalent in proximal or GOJ gastric cancer (30\% Her-2 positivity rate) and least prevalent in diffuse type gastric cancer (5\% Her2 positivity rate) (86). The RAS pathway seems to be down regulated in proximal non- diffuse gastric cancer when compared with diffuse gastric cancer $(87,88)$. The glycolysis pathway is upregulated in proximal and distal non-diffuse gastric cancers and diffuse gastric cancers are commonly FDG non-avid for PET scanning $(89,90)$. Although three pathways were dysregulated in $>70 \%$ of gastric cancer; (i) proliferation /stem cell, (ii) NF-kB and (iii) Wnt/Beta catenin, combinations of several pathways may provide greater predictive value for patient outcomes than individual pathways $(87,88)$. The clinical relevance of this new molecular classification would potentially be represented by its capability to identify prognostic and predictive biomarkers, alongside new targets for therapy (90).

\section{CONCLUSIONS}

Although multiple somatic alterations have been described in gastric carcinomas at the molecular level, the therapeutic significance remains to be established in most instances. The lack of progress in identifying new drug targets in gastric adenocarcinoma is compounded by the concomitance and heterogeneity of alterations in the neoplastic lesions, and the plasticity of hypermethylated promoters during tumour initiation and progression. In addition, failure to appreciate the biological/molecular differences of the gastric carcinoma subtypes may affect response to adjuvant treatment. The increasing concentration of the disease at the gastro- 
oesophageal junction strongly implicates reflux gastritis as an important factor but knowing which patients are at high risk and require careful assessment and review remains to be established. The role of $H$. pylori as an indicator of early diagnosis remains to be evaluated and the ability of the novel biomarkers in determining early gastric cancer should translate into improving cure rate.

\section{Ethical policies}

Compliance with Ethical Standards.

\section{Funding}

This study was not funded.

\section{Conflict of interest}

The author declare that has no conflict of interest.

\section{REFERENCES}

1. Parkin DM, Bray Fl, Ferlay J, Pisani P. Global Cancer Statistics: 2002. CA Cancer J Clin. 2005;55(2):74-108.

2. Khushalani N. Cancer of the esophagus and stomach. Mayo Clin Proc. 2008;83(6):712-22.

3. Bosetti C, Bertuccio P, Levi F, Lucchini F, Negri E, La Vecchia C Cancer mortality in the European Union, 1970-2003, with a joint point analysis. Ann Oncol. 2008;19(4):631-40. doi: 10.1093/annonc/ mdm597. Epub 2008 Feb 14.

4. de Martel C, Forman D, Plummer M. Gastric cancer: epidemiology and risk factors. Gastroenterol Clin North Am. 2013;42(2):219-40. doi: 10.1016/..gtc.2013.01.003. Epub 2013 Mar 29.

5. Fock KM. Review article: The epidemiology and prevention of gastric cancer. Aliment Pharmacol Ther. 2014;40(3):250-60. doi: 10.1111/apt.12814. Epub 2014 Jun 10.

6. Siegel R, Ma J, Zou Z Jemal A. Cancer statistics, 2014. CA Cancer J Clin. 2014;64(1):9-29. doi: 10.3322/caac.21208. Epub 2014 Jan 7 Erratum in CA Cancer J Clin. 2014;64(5):364.

7. You WC, Blot WJ, Li JY, Chang YS, Jin ML, Kneller R, et al. Precancerous gastric lesions in a population at high risk of stomach cancer. Cancer Res. 1993 Mar 15;53(6):1317-21.

8. Forman D, Burley VJ. Gastric Cancer: global pattern of the disease an overview of Environmental risk factors. Best Pract Res Clin Gastroenterol. 2006;20(4):633-49.

9. Resende C, Ristimäki A, Machado JC. Genetic and epigenetic alteration in gastric carcinogenesis. Helicobacter. 2010;15 Suppl 1: 34-9. doi: 10.1111/j.1523-5378.2010.00782.x.

10. Ferlay J, Shin HR, Bray F, Forman D, Mathers C, Parkin DM. Estimates of worldwide burden of cancer in 2008: GLOBOCAN 2008. Int J Cancer. 2010;127(12):2893-917. doi: 10.1002/ijc.25516.

11. Lauren P. The two histological main types of gastric carcinoma: diffuse and so-called intestinal-type carcinoma. An attempt at a histoclinical classification. Acta Pathol Microbiol Scand. 1965;64:31-49.

12. Correa P, Haenszel W, Cuello C, Zavala D, Fontham E, Zarama G, et al. Gastric precancerous process in a high risk population: crosssectional studies. Cancer Res. 1990; 50(15):4731-6.

13. Peek RMJ, Blaser MJ. Helicobacter pylori and gastrointestinal tract adenocarcinomas. Nature RevCancer. 2002; 2:28-37.

14. Uemura N, Okamoto S, Yamamoto S, Matsumura N, Yamaguchi S, Yamakido M, et al. Helicobacter pylori infection and the development of gastric cancer. N Engl J Med. 2001;345(11):784-9.

15. Carneiro F, Huntsman DG, Smyrk TC, Owen DA, Seruca R, Pharoah P, et al. Model of the early development of diffuse gastric cancer in E-cadherin mutation carriers and its implications for patient screening. J Pathol. 2004:203(2):681-7.

16. Blot WJ, Devesa SS, Kneller RW, Fraumeni JF Jr. Rising incidence of adenocarcinoma of the esophagus and gastric cardia. JAMA. 1991; 265(10):1287-9.

17. Crew KD, Neugut Al. Epidemiology of gastric cancer. World J Gastroenterol. 2006;12(3):354-62.

18. Muñoz N, Correa P, Cuello C, Duque E. Histologic types of gastric carcinoma in high- and low-risk areas. Int J Cancer. 1968;3(6):809-18.

19. Muñoz N, Asvall J. Time trends of intestinal and diffuse types of gastric cancer in Norway. Int J Cancer. 1971;8(1):144-57.

20. Rüdiger Siewert J, Feith M, Werner M, Stein HJ. Adenocarcinoma of the esophagogastric junction: results of surgical therapy based on anatomical/topographic classification in 1,002 consecutive patients. Ann Surg. 2000;232(3):353-61.

21. Correa P, Cuello C, Duque E. Carcinoma and intestinal metaplasia of the stomach in Colombian migrants. J Natl Cancer Inst. 1970; 44(2):297-306.

22. de Vries AC, Kuipers EJ. Epidemiology of premalignant gastric lesions: implications for the development of screening and surveillance strategies. Helicobacter. 2007;12 Suppl 2:22-31.

23. Wu X, Chen VW, Andrews PA, Ruiz B, Correa P. Incidence of esophageal and gastric cancers among Hispanics, non-Hispanic whites and non-Hispanic blacks in the United States: subsite and histology differences. Cancer Causes Control. 2007;18(6):585-93. Epub 2007 Apr 4.

24. Fennerty MB, Emerson JC, Sampliner RE, McGee DL, Hixson LJ, Garewal HS. Gastric intestinal metaplasia in ethnic groups in the south western United States. Cancer Epidemiol Biomarkers Prev. 1992;1(4):293-6.

25. Brown LM, Devesa SS. Epidemiologic trends in esophageal and gastric cancer in the United States. Surg Oncol Clin N Am. 2002; 11(2):235-56.

26. Correa P. Human gastric carcinogenesis: a multistep and multifactorial process--First American Cancer Society Award Lecture on Cancer Epidemiology and Prevention. Cancer Res. 1992;52(24): 6735-40.

27. Correa P, Piazuelo MB, Wilson KT. Pathology of gastric intestinal metaplasia: clinical implications. Am J Gastroenterol. 2010;105(3): 493-8. doi: 10.1038/ajg.2009.728.

28. Yakirevich E, Reswick MB. Pathology of gastric cancer and its precursor lesions. Gastroenterol Clin North Am. 2013;42(2):261-84. doi: 10.1016/j.gtc.2013.01.004. Epub 2013 Mar 1.

29. Watari J, Das KK, Amenta PS, Tanabe H, Tanaka A, Geng X, et al. Effect of eradication of Helicobacter pylori on the histology and cellular phenotype of gastric intestinal metaplasia. Clin Gastroenterol Hepatol. 2008;6(4):409-17. doi: 10.1016/j.cgh.2007.12.044. Epub 2008 Mar 5.

30. Gutiérrez-González L, Wright NA. Biology of intestinal metaplasia in 2008: more than a simple phenotypic alteration. Dig Liver Dis. 2008; 40(7):510-22. doi: 10.1016/j.dld.2008.02.029. Epub 2008 Apr 9.

31. Heilmann KL, Höpker WW. Loss of differentiation in intestinal metaplasia in cancerous stomachs. A comparative morphologic study. Pathol Res Pract. 1979;164(3):249-58.

32. Teglbjaerg PS, Nielsen HO. "Small intestinal type" and "colonic type" intestinal metaplasia of the human stomach, and their relationship to the histogenetic types of gastric adenocarcinoma. Acta Pathol Microbiol Scand A. 1978;86A(5):351-5.

33. Silva E, Teixeira A, David L, Carneiro F, Reis CA, Sobrinho-Simões J, et al. Mucins as key molecules for the classification of intestinal metaplasia of the stomach. Virchows Arch. 2002;440(3):311-7. Epub 2001 Dec 15.

34. Jass JR, Filipe MI. The mucin profies of normal gastric mucosa, intestinal metaplasia and its variants and gastric carcinoma. Histochem J. 1981;13(6):931-9.

35. Weledji EP, Enoworock G, Ngowe NM. Intestinal metaplasia and anastomotic recurrence of gastric carcinoma. J Gastrointest Oncol. 2014;5(6):474-80. doi: 10.3978/j.issn.2078-6891.2014.048.

36. Filipe MI, Muñoz N, Matko I, Kato I, Pompe-Kirn V, Jutersek A, et al. Intestinal metaplasia types and the risk of gastric cancer: a cohort study in Slovenia. Int J Cancer. 1994; 57(3):324-9.

37. Sarker KK, Kabir MJ, Bhuyian AKMMU, Alam MS, Chowdhury FR, Ahad MA, et al. H. pylori infection and gastric cancer in Bangladesh: a case control study. Int J Surg Oncol (N Y). 2017;2(10):e44. doi: 10.1097/IJ9.0000000000000044. Epub 2017 Oct 16. 
38. Con SA, Con-Wong R, Con-Chin GR, Con-Chin VG, Takeuchi H, Valerín AL, et al. Serum pepsinogen levels, Helicobacter pylori CagA Status, and cytokine gene polymorphisms associated with gastric premalignant lesions in Costa Rica. Cancer Epidemiol Biomarkers Prev. 2007;16(12):2631-6.

39. Eidt S, Stolte M. The significance of Helicobacter pylori in relation to gastric cancer and lymphoma. Eur J Gastroenterol Hepatol. 1995;7(4):318-21.

40. Weledji EP, Orock GE. Surgery for non-Hodgkin's lymphoma. Oncol Rev. 2015;9(1):274. doi: 10.4081/oncol.2015.274.

41. Inagaki $\mathrm{H}$, Nonaka $\mathrm{M}$, Nagaya $\mathrm{S}$, Tateyama $\mathrm{H}$, Sasaki M, Eimoto $\mathrm{T}$. Monoclonality in gastric lymphoma detected in formalin-fixed, paraffin-embedded endoscopic biopsy specimens using immunohistochemistry, in situ hybridization, and polymerase chain reaction. Diagn Mol Pathol. 1995;4(1):32-8.

42. Wotherspoon AC, Doglioni C, Diss TC, Pan L, Moschini A, de Boni $\mathrm{M}$, et al. Regression of primary low grade B-cell gastric lymphoma of mucosa associated lymphoid tissue type after eradication of Helicobacter pylori. Lancet. 1993;342(8871):575-7.

43. Stemmermann GN. Intestinal metaplasia of the stomach. A status report. Cancer. 1994;74(2):556-64.

44. Fisher SG, Davis F, Nelson R, Weber L, Goldberg J, Haenszel W. A cohort study of stomach cancer risk in men after gastric surgery for benign disease. J Natl Cancer Inst. 1993;85(16):1303-10.

45. Lundegtrdh G, Adami HO, Helmick C, Zack M, Meirik O. Stomach cancer after partial gastrectomy for benign ulcer disease. N Engl J Med. 1988; 319(4):195-200.

46. Pointner R, Schwab G, Königsrainer A, Bodner E, Schmid KW. Gastric stump cancer: etiopathological and clinical aspects. Endoscopy. 1989;21(3):115-9.

47. Northfield TC, Hall CN. Carcinoma of the gastric stump: risks and pathogenesis. Gut. 1990;31(11):1217-9.

48. Kaminishi M, Shimizu N, Shiomoyama S, Yamaguchi H, Ogawa T, Sakai $S$, et al. Etiology of gastric remnant cancer with special reference to the effects of denervation of the gastric mucosa. Cancer. 1995;75(6 Suppl):1490-6.

49. Sebagh M, Flejou JF, Potet F. Lymphoma of the gastric stump. Report of two cases and review of the literature. J Clin Gastroenterol. 1995;20(2):147-50.

50. Tanigawa N, Nomura E, Niki M, Shinohara H, Nishiguchi K, Okuzawa $\mathrm{M}$, et al. Clinical study to identify specific characteristics of cancer newly developedin the remnant stomach. Gastric Cancer. 2002; 5(1): 23-8.

51. Johannesson KA, Hammar E, Staël von Holstein C. Mucosal changes in the gastric remnant: long-term effects of bile reflux diversion and Helicobacter pylori infection. Eur J Gastroenterol Hepatol. 2003;15(1):35-40.

52. Rokkas T, Filipe MI, Sladen GE. Detection of an increased incidence of early gastric cancer in patients with intestinal metaplasia type III who are closely followed up. Gut. 1991:32(10):1110-3.

53. Park JH, Lee JH, Rhee PL, Kim JJ, Rhee JC, Kim S, et al. Endoscopic Screening for Remnant Gastric Cancer: Points to be considered. Gut Liver. 2007;1(1):22-6. doi: 10.5009/gnl.2007.1.1.22. Epub 2007 Jun 30.

54. Matsukura N, Suzuki K, Kawachi T, Aoyagi M, Sugimura T, Kitaoka $\mathrm{H}$, et al. Distribution of marker enzymes and mucin in intestinal metaplasia in human stomach and relation to complete and incomplete types of intestinal metaplasia to minute gastric carcinomas. J Nat Cancer Inst. 1980;65(2):231-40.

55. Wu HH, Lu WC, Tsai KW. Advances in molecular biomarkers for gastric cancer: mi RNAs as emerging novel cancer marker. Expert Rev Mol Med. 2014;16:e1. doi: 10.1017/erm.2013.16.

56. Ming S-C. Malignant potential of epithelial polyps of the stomach. In Ming S-C (ed) Precursors of gastric cancer. New York: Praeger; 1984. p. 219-31.

57. Nakamura T, Nakano Gl. Histopathological classification, and malignant change in gastric polyps. J Clin Pathol. 1985;38(7):754-64.

58. Hattori T. Morphological range of hyperplastic polyps and carcinomas arising in hyperplastic polyps of the stomach. J Clin Pathol. 1985;38(6):622-30.

59. lida M, Yao T, Watanabe $\mathrm{H}$, Itoh $\mathrm{H}$, Iwashita A. Fundic gland polyposis in patients without familial adenomatosis coli: its incidence and clinical features. Gastroenterology. 1984;86(6):1437-42.

60. Kolodziejczyk P, Yao T, Oya M, Nakamura S, Utsunomiya T, Ishikawa $\mathrm{T}$, et al. Long-term follow-up study of patients with gastric adenomas with malignant transformation. An immunohistochemical and histochemical analysis. Cancer. 1994; 74(11):2896-907.

61. Sarre RG, Frost AG, Jagelman DG, Petras RE, Sivak MV, McGannon E. Gastric and duodenal polyps in familial adenomatous polyposis. A prospective study of the nature and prevalence of upper gastrointestinal polyps. Gut. 1987;28(3):306-14.

62. Morson BC, Sobin LH, Grundmann E, Johansen A, Nagayo T, SerckHanssen A. Precancerous conditions and epithelial dysplasia in the stomach. J Clin Pathol. 1980;33(8):711-21.

63. Coma del Corral MJ, Pardo-Mindan FJ, Razquin S, Ojeda C. Risk of cancer in patients with gastric dysplasia: follow-up study of 67 patients. Cancer. 1990;65(9):2078-85.

64. Antonioli DA. Precursors of gastric carcinoma: a critical review with a brief description of early (curable) gastric cancer. Hum Pathol. 1994:25(10):994-1005.

65. Lee S, lida M, Yao T, Shindo S, Okabe H, Fujishima M. Long-term follow-up of 2529 patients reveals gastric ulcers rarely become malignant. Dig Dis Sci. 1990; 35(6):763-8.

66. Johnson MI, Spark JL, Ambrose NS, Wyatt Jl. Early gastric cancer in a patient with Menetrier's disease, lymphocytic gastritis and Helicobacter pylori. Eur J Gastroenterol Hepatol. 1995;7(2):187-90.

67. Tahara E. Genetic alterations in human gastrointestinal cancers. The application to molecular diagnosis. Cancer. 1995;75(6 Suppl):1410-7.

68. Wright PA, Quirke P, Attanoos R, Williams GT. Molecular pathology of gastric carcinoma: progress and prospects. Hum Pathol. 1992; 23(8):848-59.

69. Yonemura $\mathrm{Y}$, Matsumoto $\mathrm{H}$, Ninomiya I, Ohoyama S, Kimura H, de Aletxabala $X$, et al. Heterogeneity of DNA ploidy in gastric cancer. Anal Cell Pathol. 1992;4(2):61-7.

70. Wright PA, Williams GT. Gastric carcinoma. In; Quirke P (Ed) Molecular biology of digestive disease, 1st edn. London: BMJ Publishing Group; 1994. p. 44-51.

71. Noguchi Y, Tsuburaya A, Makino T, Fukuzawa K, Nomura K, Yoshikawa $\mathrm{T}$, et al. Predictive value of c-erbB-2 and DNA ploidy patterns in gastric carcinoma recurrence. Int Surg. 1993;78(2):107-11.

72. Stemmermann G, Heffelfinger C, Nofsinger A, Zhong Y, Miller MA, Fenoglio-Prieser CM. The molecular biology of esophageal and gastric cancer and their precursors: oncogenes, tumour suppressor genes and growth factors. Hum Pathol. 1994;25(10):968-81.

73. Tamura G, Sakata K, Maesawa C, Suzuki Y, Terashima M, Satoh K, et al. Microsatellite alterations in adenoma and differentiated adenocarcinoma of the stomach. Cancer Res. 1995;55(9):1933-6.

74. Kastan MB, Onyekwere O, Sidransky D, Vogelstein B, Craig RW. Participation of p53 protein in the cellular response to DNA damage. Cancer Res. 1991: 51(23 Pt 1):6304-11.

75. Greenblatt MS, Bennett WP, Hollstein M, Harris CC. Mutations in the p53 tumour suppressor gene: clues to cancer etiology and molecular pathogenesis. Cancer Res. 1994;54(18):4855-78.

76. Harn HJ, Ho LI, Chang JY, Wu CW, Jiang SY, Lee HS, et al. Differential expression of the human metastasis adhesion molecule CD44V in normal and carcinomatous stomach mucosa of Chinese subjects. Cancer. 1995;75(5):1065-71.

77. BerX G, Becker KF, Höfler H, van Roy F. Mutations of the human E-cadherin (CDH1) gene. Hum Mutat. 1998;12(4):226-37.

78. Machado JC, Soares P, Carneiro F, Rocha A, Beck S, Blin N, et al. E-cadherin gene mutations provide a genetic basis for the phenotypic divergence of mixed gastric carcinomas. Lab Invest. 1999; 79(4):459-65.

79. Guilford P, Hopkins J, Harraway J, McLeod M, McLeod N, Harawira $P$, et al. E-cadherin germline mutations in familial gastric cancer. Nature. 1998;392(6674):402-5.

80. Oliveira C, Bordin MC, Grehan N, Huntsman D, Suriano G, Machado $\mathrm{JC}$, et al. Screening of E-Cadherin in gastric cancer families reveals germ-line mutations only in hereditary diffuse gastric cancer kindred. Hum Mutat. 2002;19(5):510-7.

81. Oliveira C, Sousa S, Pinheiro H, Karam R, Bordeira-Carrico R, Senz $J$ et al. Quantification of epigenetic and genetic 2nd Hits in $\mathrm{CDH} 1$ during hereditary diffuse gastric cancer syndrome progression. 
Gastroenterology. 2009;136(7):2137-48. doi: 10.1053/j.gastro 2009.02.065. Epub 2009 Mar 6.

82. Shah MA, Khanin R, Tang L, Janjigian YY, Klimstra DS, Gerdes H, et al. Molecular classification of Gastric Cancer: A new paradigm. Clin Cancer Res. 2011;17(9):2693-701. doi: 10.1158/1078-0432.CCR10-2203. Epub 2011 Mar 23.

83. Sakaguchi T, Watanabe A, Sawada H, Yamada Y, Tatsumi M, Fujimoto $\mathrm{H}$, et al. Characteristics and clinical outcome of proximal-third gastric cancer. J Am Coll Surg. 1998;187(4):352-7.

84. Marrelli D, Roviello F, de Manzoni G, Morgagni P, Di Leo A, Saragoni $\mathrm{L}$, et al. Different patterns of recurrence in gastric cancer gdepending on Lauren's histologic type: longitudinal study. World J Surg. 2002; 26(9):1160-5. Epub 2002 Jun 25.

85. Hofmann M, Stoss O, Shi D, Büttner R, van de Vijver M, Kim W, et al. Assessment of a Her2 scoring system for gastric cancer: results from a validation study. Histopathology. 2008;52(7):797-805. doi: 10.1111/.1365-2559.2008.03028.x. Epub 2008 Apr 18.

86. Ooi CH, Ivanova T, Wu J, Lee M, Tan IB, Tao J, et al. Oncogenic pathway combinations predict clinical prognosis in gastric cancer. PLoS Genet. 2009;5(10):e1000676. doi: 10.1371/journal.pgen. 1000676. Epub 2009 Oct 2.

87. Hiyama T, Haruma K, Kitadai Y, Masuda H, Miyamoto M, Tanaka S, et al. K-ras mutation in helicobacter pylori-associated chronic gastritis in patients with and without gastric cancer. Int J Cancer. 2002; 97(5):562-6.

88. Vander Heiden MG, Cantley LC, Thompson CB. Understanding the Warburg effect: the metabolic requirements of cell proliferation. Science. 2009;324(5930):1029-33. doi: 10.1126/science.1160809.

89. Shah MA, Yeung $\mathrm{H}$, Coit D, et al. A phase II study of preoperative chemotherapy with irinotecan (CPT) and cisplatin (CIS) for gastric cancer (NCI 5917): FDG-PET/CT predicts patient outcome. American Society of Clinical Oncology, Annual Proceedings; Orlando, FL. 2007

90. Wu CW, Li AF, Chi CW, Huang CL, Shen KH, Liu WY, et al. Human gastric cancer kinase profile and prognostic significance of MKK4 kinase. Am J Pathol. 2000;156(6):2007-15. 